\title{
Spatial allocation effects within a potentization basic research model - evidence for field-like effects of homeopathic preparations?
}

\author{
Stephan Baumgartner 1,2,3, Lucietta Betti 4, Mascha Binder 1,5, \\ Peter Heusser ${ }^{2}$, Ursula Wolf ${ }^{1}$ \\ ${ }^{1}$ Institute of Complementary Medicine, University of Bern, Bern, Switzerland \\ 2 Institute of Integrative Medicine, University of Witten-Herdecke, Herdecke, Germany \\ ${ }^{3}$ Hiscia Institute, Society for Cancer Research, Arlesheim, Switzerland \\ ${ }_{4}^{4}$ Department of Agricultural Sciences, University of Bologna, Bologna, Italy \\ 5 Dept. Hematological Oncology, University Medical Center Hamburg-Eppendorf, Germany
}

Background: The mode of action of ultramolecular homeopathic preparations is still unknown. Interactions between objects or entities can be grouped in four main general scientific categories: material, force-/field-like, entanglement-like or informational. Should homeopathic preparations have a field-like mode of action, there is greater probability of cross-contamination as long as the means to "shield" objects from each other is unknown. A field-like interaction would also lead to treatment at a distance effects that are distancedependent. Aims: We analysed a set of experiments with Arsenicum album 45x treated wheat seedlings regarding a possible distance-dependent cross-contamination. Materials and Methods: We performed an $a$ posteriori analysis of a set of 17 independent experiments [1,2] with wheat seedlings pre-treated with $1 \%$ arsenic. Three treatments were applied (Arsenicum album 45x, water 45x, or unpotentized water) with 150 seedlings in each treatment group per experiment. Seedlings were arranged in hanging plastic bags side-byside in identically treated blocks of 10 seedlings. The $3 \times 15$ blocks were coded and randomly allocated to the three treatments. Wheat shoot length was measured after 7 days. Treatment effects were analysed as function of the position (1-10) within the blocks of 10 seedlings. Results: Analyzing all data, Arsenicum album $45 \mathrm{x}$ exerted an inhibiting effect $(-3.2 \%, \mathrm{p}=0.01)$ compared to both water and water $45 \mathrm{x}$. When restricting the analysis to the outermost seedlings of all subgroups (pos. 1, 10), the treatment effect vanished $(0.3 \%, p=0.92)$. In contrast, the innermost seedlings of all subgroups (pos. 5,6$)$ showed a treatment effect of $5.6 \%(\mathrm{p}=0.02)$. Intermediate pairs of positions (pos. 2-4, 7-9) showed intermediate effects. Regarding shoot length, dependency on spatial position was observed for the plants of the water control groups, but not for the plants treated with Arsenicum album 45x. Conclusions: Whilst the effect of Arsenicum album 45x on wheatshoot growth was not dependent on the spatial position within the subgroup, the water-control plants became smaller the closer they were to Arsenicum album 45x-treated seedlings. This observation is compatible with the existence of a field-like effect of homeopathic dilutions. Another possible explanation that cannot be ruled out by the present experiments, is contamination through the gas-phase. Future investigations of ultramolecular homeopathic preparations should control any such effects since they may mask treatment effects, leading to false-negative results. Closer investigation of the nature of this distance-dependent effect might contribute to identification of the mode of action of ultramolecular homeopathic preparations.

Keywords: Arsenicum album, mode of action, contamination

References: 
[1] Binder M, Baumgartner S, Thurneysen A. The Effects of a 45x Potency of Arsenicum album on Wheat Seedling Growth - a Reproduction Trial. Forsch Komplentarmed Klass Naturheilkd. 2005;12(5):284-91.

[2] Lahnstein L, Binder M, Thurneysen A, Frei-Erb M, Betti L, Peruzzi M, et al. Isopathic treatment effects of Arsenicum album 45x on wheat seedling growth--further reproduction trials. Homeopathy. 2009;98(4):198207.

\section{(c)) EY-NC-ND Licensed to GIRI}

Support: There were no external sources of funding for this study

Conflict of interest:The authors declare that there is no conflict of interest.

Received: March 30 ${ }^{\text {th }} 2014$; Revised: May 10 ${ }^{\text {th }}$ 2014; Published: June $30^{\text {th }} 2014$.

Corresponding author: Stephan Baumgartner, stephan.baumgartner@ikom.unibe.ch

How to cite this article: Baumgartner S, Betti L, Binder M, Heusser P, Wolf U.Spatial allocation effects within a potentization basic research model - evidence for field-like effects of homeopathic preparations? Int J High Dilution Res [online]. 2014 [cited YYYY Month dd]; 13(47):86-87. Proceedings of the XXVIII GIRI Symposium; 2014 Jun 20-22; Sighisoara (Romania). GIRI; 2014; Available from: http://www.feg.unesp.br/ ojs/index.php/ijhdr/article/view/748/722 